\title{
Study on the Bearing Capacity and Engineering Performance of Aeolian Sand
}

\author{
Han Xia ${ }^{D},{ }^{1}$ Jingtao Zhang, ${ }^{2,3}$ Jun Cai, ${ }^{1}$ Huangsong Pan, ${ }^{1}$ and Xuesen She ${ }^{3}$ \\ ${ }^{1}$ School of Transportation, Southeast University, Nanjing 211189, China \\ ${ }^{2}$ CCCC First Highway Consultants Co., Ltd, Xi'an 710075, China \\ ${ }^{3}$ Highway School, Chang'an University, Xi'an 710061, China \\ Correspondence should be addressed to Han Xia; evansha@126.com
}

Received 7 October 2019; Revised 21 March 2020; Accepted 1 April 2020; Published 30 April 2020

Academic Editor: Antonio Boccaccio

Copyright ( 92020 Han Xia et al. This is an open access article distributed under the Creative Commons Attribution License, which permits unrestricted use, distribution, and reproduction in any medium, provided the original work is properly cited.

\begin{abstract}
The climate in the aeolian desert has great differences from that in other regions, generally showing large diurnal temperature differences and extremely dry and low groundwater level characteristics. Therefore, the physical and mechanical characteristics of the sand are different from those of other regions, and it has a loose soil structure, large pores, and a low bearing capacity. To ensure the security and applicability of engineering, it is necessary to study the engineering characteristics of aeolian sand. This paper focuses on the bearing capacity parameters of aeolian sand in the Mu Us Desert, and test sites in 6 weak foundation areas are selected. Large numbers of basic soil mechanical parameters have been collected through in situ static load tests (SLT) and laboratory confined compaction tests (CCT) to evaluate the effect of foundation treatments. The results show that the characteristics of aeolian sand in the Mu Us Desert include low moisture, poor cohesion, and easy compaction. The mud and water content affect the bearing capacity of aeolian sand. For weak foundations, adding a geogrid or replacing a weak soil layer with stone and aeolian sand can significantly improve the bearing capacity.
\end{abstract}

\section{Introduction}

Aeolian sand is one of the most important types of sand foundations in engineering design, and it is characterized by small size particles, low cohesion, low shear strength, strong permeability, and poor self-stability. Aeolian sand is a kind of quaternary sediment formed by sand particle movement due to wind that eventually gathered in a region [1]. For sandy soil foundations, the bearing capacity is the most important parameter. Aeolian sand occupies a large area in the world; therefore, as a valuable available land resource, aeolian sand can be used for engineering construction as long as its basic properties are obtained and its treatment is modified. In the past, many researchers [2-6] used micrometeorological data to study small sand dunes.

Khan [7] was the first to study the engineering properties of aeolian sand, conduct geotechnical tests, and chemical analyses on samples from different locations in the Sahara Desert. Al-Sanad $[8,9]$ carried out classification tests on the compaction characteristics, permeability, compressibility, and shear strength in Kuwait. Al-Harthy [9, 10] tested the workability, compressive strength, tensile strength, modulus of elasticity, and initial surface absorption test (ISAT) of aeolian sand. Zhang [11] studied the compression deformation of aeolian sand and found that the compression deformation was small, the compression amount was exponentially related to the load, and the elastic modulus of aeolian sand was large. Yuan [12] and Chen [13] studied the vibration compaction characteristics of aeolian sand with the vibration method and found that the optimal vibration frequency of aeolian sand was $45-50 \mathrm{~Hz}$ under dry conditions and optimal water content. Jiang [14] showed that the chemical composition of aeolian sand was mainly composed of silica (65-86\%), alumina (8-10\%), and other substances, such as iron oxide and calcium oxide, in China. Al-Ansary [15] found that Qatar sand contains a large amount of carbonate rocks and a small amount of clay minerals. Seif [16] also found that the percentage of sulfates and chlorides 
found in the Egyptian Desert is so low that it is negligible. Padmakumar [17] suggested that aeolian sand used for concrete mixing in the Thar Desert in India is less likely to collapse because of the high angle of internal friction. Yang's research showed that aeolian sand has good permeability, the maximum water absorption rate is not more than $1.0 \%$, and almost no viscous particles are formed [18]. LopezQuerol [19] introduced various methods to improve these materials and their outcomes and limitations.

The $\mathrm{Mu}$ Us Desert is located at $37^{\circ} 27^{\prime}-39^{\circ} 22^{\prime} \mathrm{N}$ and $107^{\circ} 20^{\prime}-111^{\circ} 30^{\prime} \mathrm{E}$, and the total area is approximately $4.22 \mathrm{~km}^{2}$. This region is above $1100-1300 \mathrm{~m}$ in elevation, the annual average temperature is between $6.0^{\circ} \mathrm{C}$ and $8.5^{\circ} \mathrm{C}$, and the annual precipitation is between $250 \mathrm{~mm}$ and $440 \mathrm{~mm}$ [20]. Wang [21] found that the aeolian sand-heavy mineral assemblage in the central and northern parts of the Mu Us Desert is different from that in the southwest part, indicating that the sources of aeolian sand-heavy mineral assemblage are obviously different.

In this paper, a large amount of measured data have been collected to show the basic characteristics of aeolian sand in the $\mathrm{Mu}$ Us Desert. In addition, a study on the variation in the soil properties with different ground improvement methods was presented. Six areas have been investigated in the Mu Us Desert, and those foundations have been reinforced by 6 methods used in each area. Then, the reinforcement effect was evaluated by a series of in situ and laboratory tests.

\section{Test Methods}

2.1. Testing Site. Six poor foundations were selected as test areas and were located at the edge of the Mu Us Desert (see Figure 1). According to the engineering geology survey, the groundwater level in the 6 test sites was generally no higher than $1 \mathrm{~m}$. During the construction period, due to the decrease in precipitation, the weather was dryer than that at other times, the groundwater level slightly decreased, but the water content of the foundation was still high. The existence of humus leads to soil that contains many pores, which reduces the soil strength. According to the differences in the soil thickness and height of the subgrade filling, the treatment schemes were different. These sand layers were affected by groundwater for a long time, which led to softer and weaker natural foundations (Figure 2).

To ensure that the postconstruction settlement and stability of the subgrade meet the standard design requirements, it is necessary to carry out field and laboratory tests to evaluate the bearing capacity and propose a satisfactory treatment method for each area to reinforce the weak foundation.

Table 1 shows the basic physical and mechanical parameters in each area before the compaction test. Obviously, the moisture content of area 2 is significantly higher than that of the other areas, and the void ratio is significantly higher than that of the other areas. The moisture content of area 5 is slightly lower than that of the other areas, and the void ratio is correspondingly smaller than that of the other areas. The void ratio of area 2 clearly changed with the increase in pressure. Area 2 has a larger water content

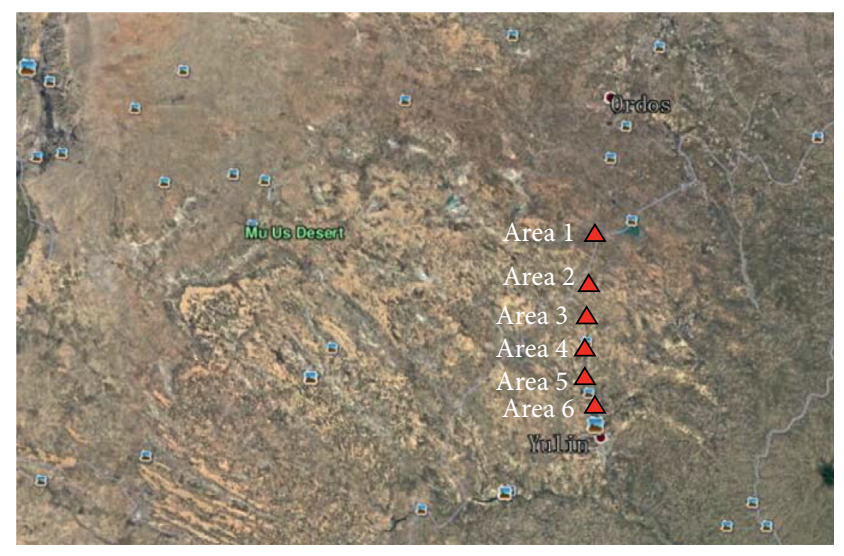

FIgURE 1: Test site in the Mu Us Desert of China (https://map. google.com).

(reaching 50.86\%), and the essence of the soil deformation is mainly from pore water and air in the soil; therefore, under the same pressure in this area, the soil settles faster than the others. Compared with other areas, the moisture content of $29.14 \%$ is larger for aeolian sand foundation, the void ratio changes are more obvious, and the settlement is the same in area 1 ; for area 4 , area 3 , area 6 , and area 5 , the water content was $24.02 \%, 22.76 \%, 21.50 \%$, and $16.27 \%$. The water content decreased in turn, and the void ratio also decreased in turn.

The basic parameters of aeolian sand throughout the world are shown in Table 2. The specific gravity is higher than that in the Qatar and Sahara Deserts, and the specific gravity and void ratio are lower than those in the Thar Desert.

2.2. Sieve Analysis. Figure 3 shows the particle size distribution in the test areas according to the sieve analysis. It is clear that the soil particle sizes are mainly arranged from $0.075 \mathrm{~mm}$ to $2 \mathrm{~mm}$, which means that the poor foundation is mainly composed of silty sand, fine sand, and sand with mud.

For a more in-depth analysis, the effect of the strength of poor foundations with fine particles and mud content $(\leq 0.02 \mathrm{~mm})$ was tested, and the results are shown in Table 3 . It was determined that a large amount of mud exists in the weak foundation area.

2.3. Reinforcement Methods. According to the original design, all of the soft soil layers of the weak foundation areas were replaced with aeolian sand. However, the results of the 6 typical weak foundation areas indicated that the moisture, mud content, and particle size distribution were significantly different from each other. Even when using the same reinforcement methods, these six foundations may not be capable of achieving the bearing capacity required for design. Considering the complex effect of the former research, the 6 reinforcement methods (Table 4) were tested by SLTs and CCTs to test their applicability.

Table 5 shows the filling height and poor foundation thickness of the 6 test areas. The filling height of this expressway is from $2.04 \mathrm{~m}$ (area 2) to $5.20 \mathrm{~m}$ (area 3); the poor 


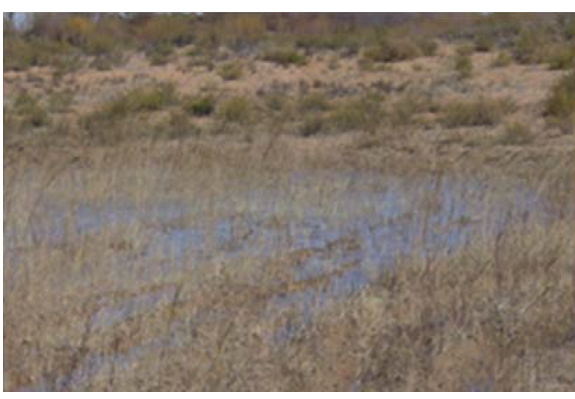

(a)

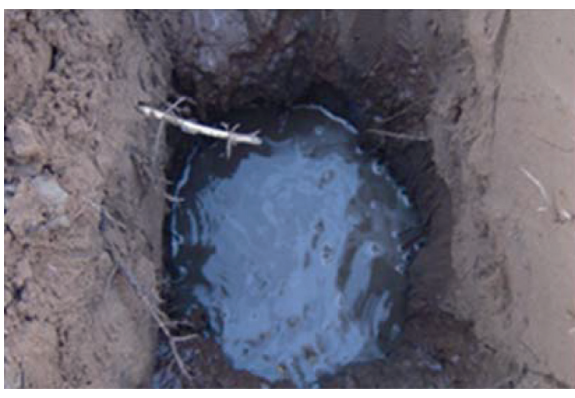

(b)

Figure 2: Weak soil in the test area.

TABle 1: Basic physical parameters.

\begin{tabular}{lcccc}
\hline Area & $W / \%$ & $\rho / \mathrm{g} / \mathrm{cm}^{3}$ & $e$ & $G s$ \\
\hline 1 & 29.14 & 1.986 & 0.74 & 2.68 \\
2 & 50.86 & 1.740 & 1.29 & 2.67 \\
3 & 22.76 & 1.986 & 0.65 & 2.67 \\
4 & 24.02 & 1.745 & 0.60 & 2.68 \\
5 & 16.27 & 2.141 & 0.46 & 2.69 \\
6 & 21.50 & 2.136 & 0.52 & 2.68 \\
Mean & 27.43 & 1.956 & 0.71 & 2.68 \\
\hline
\end{tabular}

TABLE 2: The basic parameters of aeolian sand in different locations.

\begin{tabular}{lcccc}
\hline Site & $W / \%$ & $\rho / \mathrm{g} / \mathrm{cm}^{3}$ & $e$ & $G s$ \\
\hline Mu Us Desert & 27.43 & 1.956 & 0.71 & 2.68 \\
Qatar [15] & - & - & - & 2.60 \\
Sahara Desert [16] & - & - & - & 2.41 \\
Thar Desert [17] & - & - & 0.79 & 2.79 \\
\hline
\end{tabular}

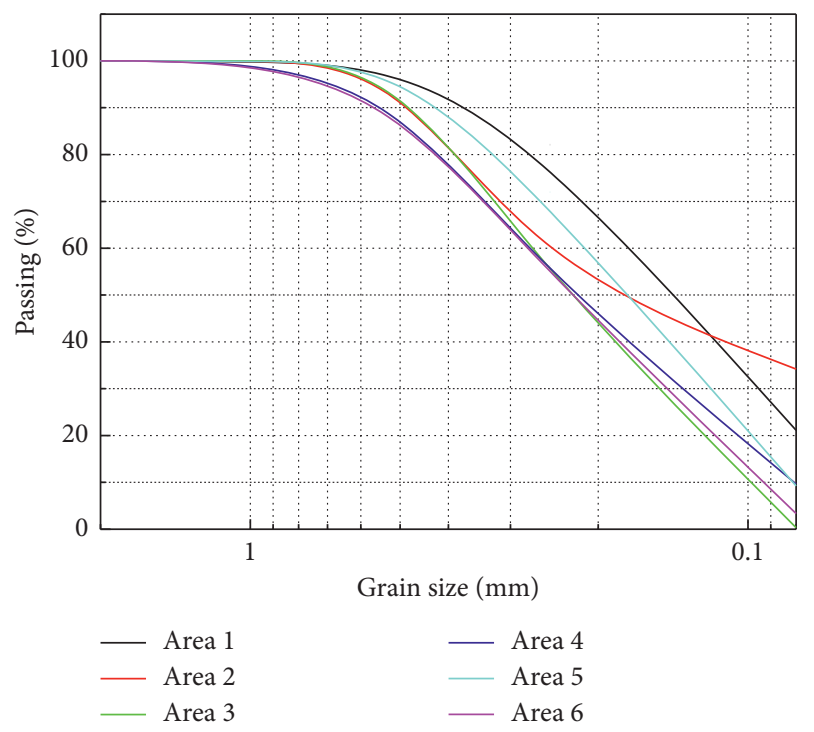

FIGURE 3: Grain distribution.

foundation thickness is from $0 \mathrm{~m}$ (area 4) to $5 \mathrm{~m}$ (area 1 and area 6). Each area ensures that at least one point is in natural ground or filled subgrade, as detailed in Figure 4.
Table 3: Mud content in each testing area.

\begin{tabular}{lcccc}
\hline Area & \multicolumn{3}{c}{ Mud content/\% } & Average/\% \\
\hline 1 & 63.3 & 49.2 & 91.7 & 68.1 \\
2 & 53.4 & 61.2 & 61.5 & 58.7 \\
3 & 57.5 & 58.4 & 58.1 & 58.0 \\
4 & 17.5 & 19.3 & 16.5 & 17.8 \\
5 & 43.9 & 41.3 & 42.4 & 42.5 \\
6 & 46.1 & 49.2 & 31.4 & 42.2 \\
\hline
\end{tabular}

\section{FEM Analysis}

To analyze the effect of different foundation treatment methods, a series of two-dimensional numerical analyses was used to model the settlement of each area. The parameters used in the numerical simulation are consistent with the experimental parameters (Table 1). The settlement of the 6 foundation treatment methods was modeled at $200 \mathrm{kPa}$.

The numerical modeling results are shown in Figure 5. The noncompact settlement in the 6 areas is between 4.80 and $5.83 \mathrm{~cm}$. The large settlement indicated that the foundation needed to be compacted after treatment. The minimum settlement is in area 1 , and the maximum settlement is in area 4 . This phenomenon is mainly because a $1 \mathrm{~m}$ stone cushion was filled at the bottom in area 1 , and there was no treatment method for area 4 . The numerical modeling results also indicated that the bearing capacity of aeolian sand was relatively high, and replacing aeolian sand could significantly improve the strength of the subgrade. Stone and gravel fill under the replaced aeolian sand layer can efficiently improve the bearing capacity of the subgrade.

\section{Test Methods and Procedures}

4.1. Static Load Test (SLT). The static load test is a common test for the foundation bearing capacity, which can be used to determine the allowable bearing capacity of highway foundation soil and bridge culvert soil [22]. The experimental objective is to determine the deformation modulus of soil under the natural occurrence condition with a certain vertical pressure, the deformation of the soil that is dependent on the time, and the estimated bearing capacity when the load is close to the actual foundation condition. 
TABLE 4: Reinforcement methods for each area.

\begin{tabular}{lr}
\hline Area & Reinforcement methods \\
\hline 1 & One meter was filled with a stone cushion and $2 \mathrm{~m}$ of aeolian sand were replaced \\
2 & Two meters of aeolian sand were replaced and a geogrid was added \\
3 & One meter was filled with a stone cushion, $2 \mathrm{~m}$ of aeolian sand were replaced, and a geogrid was added \\
4 & Two meters of aeolian sand were replaced \\
5 & The silt was removed below $2 \mathrm{~m}, 2 \mathrm{~m}$ of gravel was filled, a geogrid was added, and then, aeolian sand was filled to the surface \\
6 &
\end{tabular}

TABLE 5: Fill height and poor foundation thickness in each testing area.

\begin{tabular}{lcr}
\hline Area & Height of filling/m & Poor foundation thickness $/ \mathrm{m}$ \\
\hline 1 & $4.00-5.17$ & $3.0-5.0$ \\
2 & $2.04-3.61$ & $1.0-3.0$ \\
3 & $5.20-5.36$ & 2.0 \\
4 & $4.20-5.06$ & 0.0 \\
5 & $2.07-3.65$ & 1.2 \\
6 & $2.51-2.82$ & $4.0-5.0$ \\
\hline
\end{tabular}

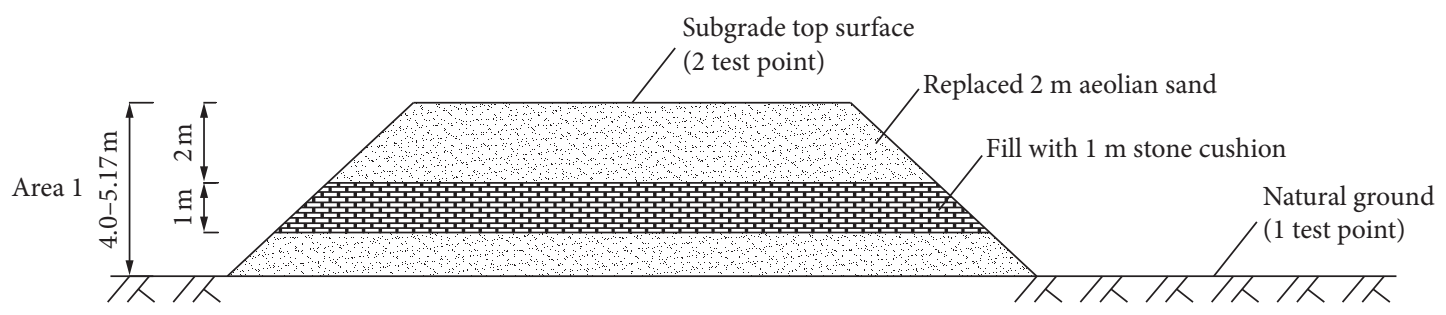

(a)

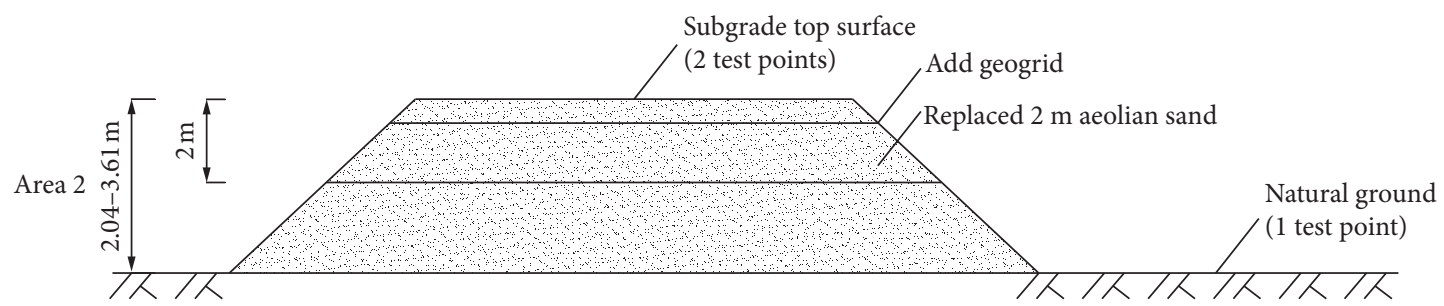

(b)

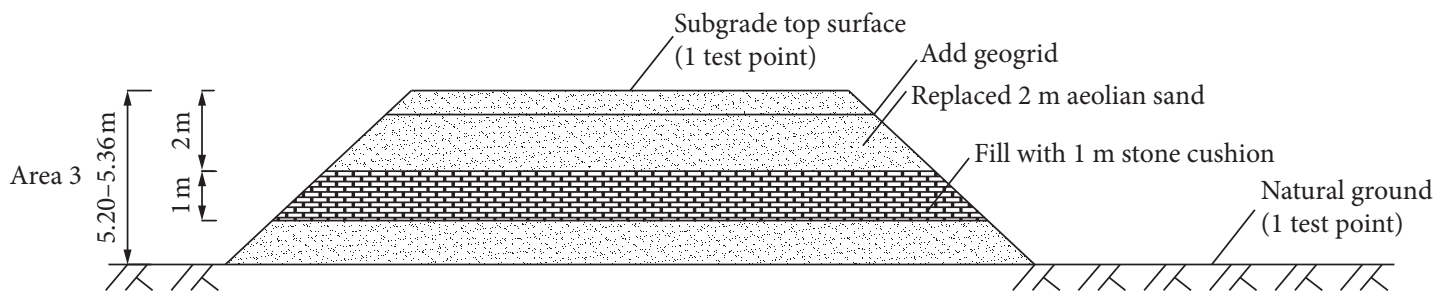

(c)

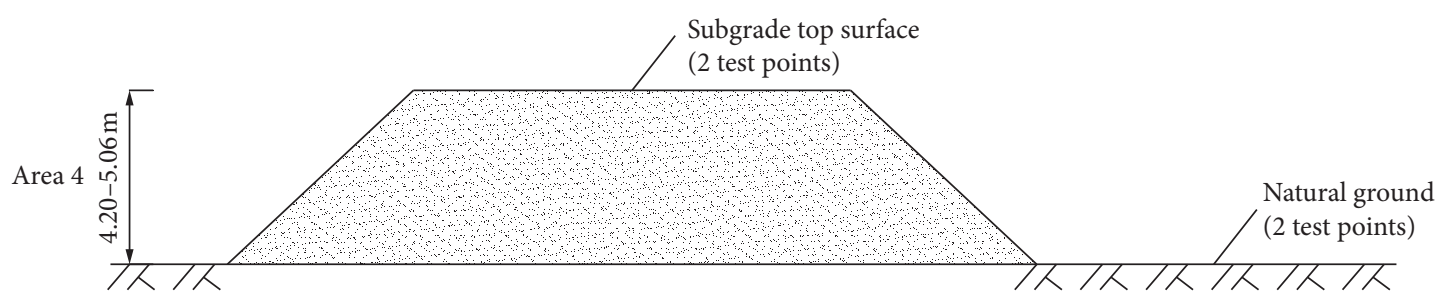

(d)

Figure 4: Continued. 


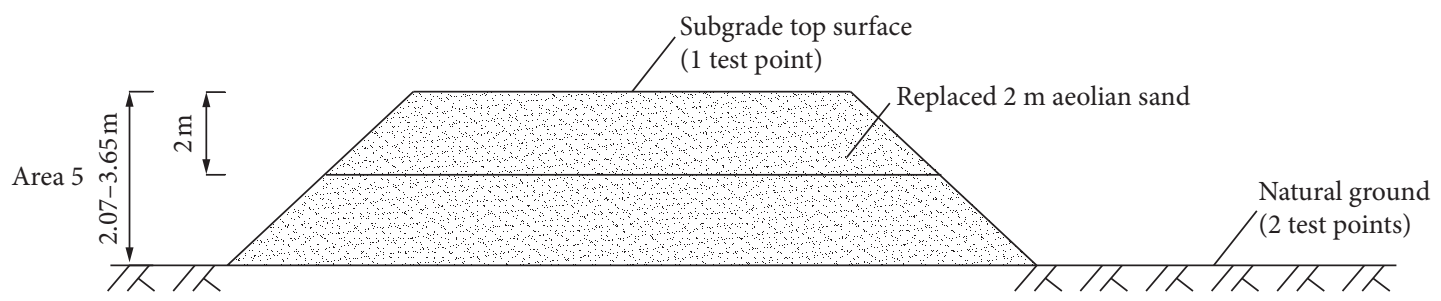

(e)

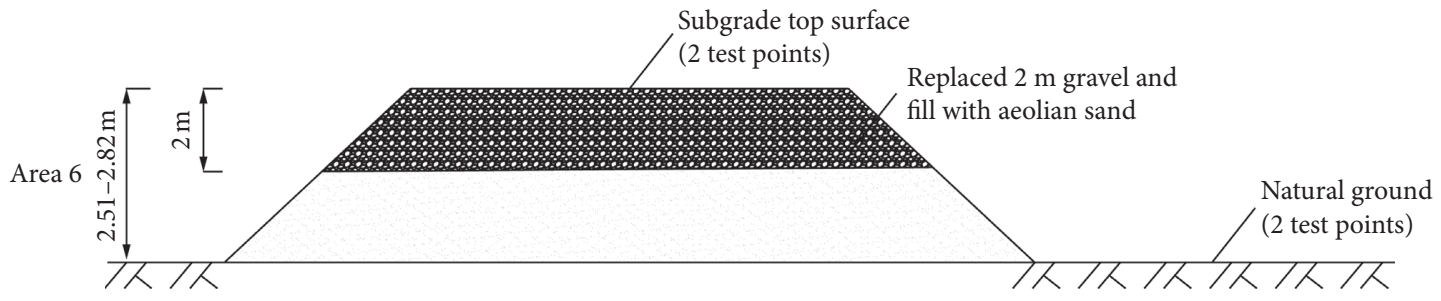

(f)

FIgURE 4: Test points and reinforcement method in each testing area.

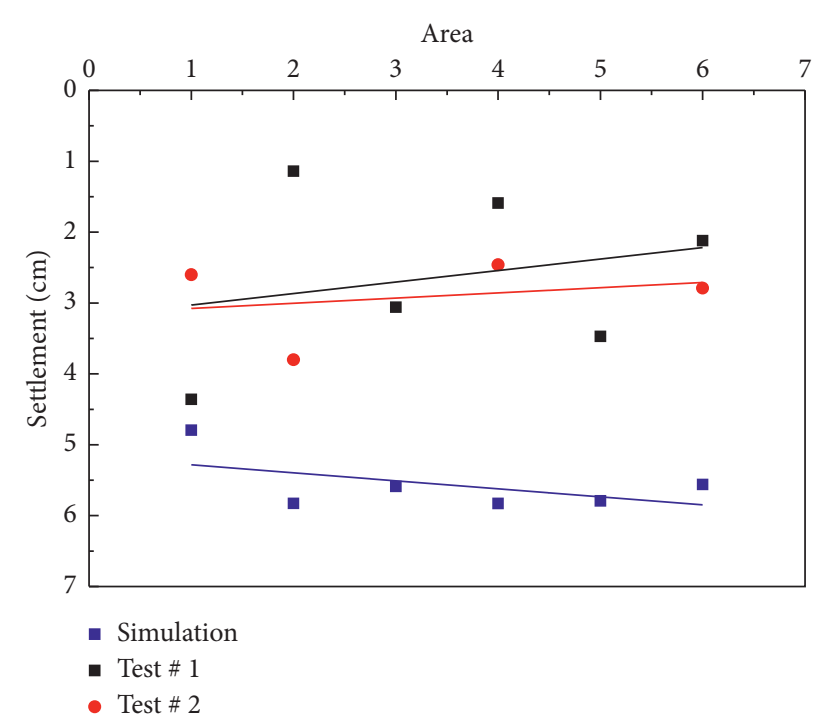

FIgURE 5: Numerical analysis results at $200 \mathrm{kPa}$.

The results can be used to obtain the pressure-settlement curve and deformation modulus. This method of determining the bearing capacity of a foundation by means of loading tests is based on the pressure corresponding to the characteristic points of the $p-s$ curve and two feature points from which, for medium and high compressibility soil foundations, the local damage is in the form of compression shear failure or punching failure[23]. At this time, there is no obvious characteristic point on the $p$-s curve, and the allowable bearing capacity stress of the foundation soil can be obtained by using the following equation[22]:

$$
\frac{S}{B}=0.02 \text {, }
$$

where $S$ is the settlement, $s$ on the $p$-s curve, and $B$ is the width of the bearing plate (or diameter).
The settlement of aeolian sand will be smaller than that of ordinary soils; thus, the following equation can be used [22]:

$$
\frac{S}{B}=0.01 \sim 0.15
$$

The test vehicle is drawn to the test position, and aeolian sand is installed in the car as a counterweight to meet the test reaction force. A loading plate is arranged in the circular pit and corrected by a horizontal level to ensure that the bearing plate is in a horizontal state. A fixed stiffening beam is used to align the center of the bearing plate with the suspended vertical balls. The jack is placed on the center of the bearing plate, steel cylinder, steel plate, and ball on the top of the stiffening beam. The sensor is placed between the middle surface of the jack and the stiffening beam, and the Jack remains vertical so that the sack can tilt, which affects the accuracy of the test data. The devices are shown in Figure 6.

Before the experiment started, the jack loading was $10 \mathrm{kN}$, which meant that the bearing force was $50 \mathrm{kPa}$ at that time. Then, the pressure was held for 1 minute, and the bearing plate and the subgrade were in close contact. Next, unloading for 1 minute resulted in zero displacement meter readings. Using the step by step jack loading and sensors to control the load force, each load increment was $1 / 8-1 / 10$ of the preestimated value of the soil ultimate bearing capacity. Accordingly, considering the actual situation of the embankment to a load of $10 \mathrm{kN}$ in each stage, natural foundation loading occurred in $5 \mathrm{kN}$ increments to $10 \mathrm{kN}$ in each stage.

The test is completed when the following circumstances occur: (1) the soil around the bearing plate rises or cracks appear; (2) the total settlement is more than $0.1 B$ ( $B$ is the width or diameter of the bearing plate); (3) the total loading has reached more than 2 times the design requirements. During unloading, the unloading amount of each stage is 2 times the loading increment, which lasts for 1 hour. 


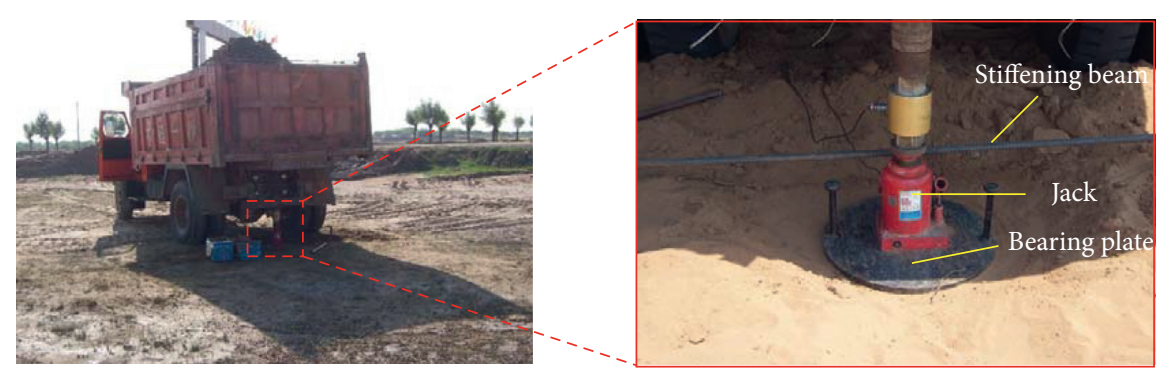

Figure 6: Test point and equipment.

During the first 30 minutes of loading, settlement was observed once every 10 minutes; during the second 30 minutes, settlement was observed once every 15 minutes; and later, settlement was observed once every 30 minutes. When the cumulative settlement was less than $0.1 \mathrm{~mm}$ per hour, the next load could be applied. The unloading was observed once every 15 minutes.

4.2. Confined Compaction Test (CCT). The soil deformation and settlement are closely related to the compression performance of the soil, and the natural soil is composed of three parts: soil particles, water, and gas [24]. To estimate the settlement of aeolian sand subgrade, the following compressibility indexes should be obtained in the compression test: compression coefficient a, compression modulus Es, and compression index $C c$.

The compression coefficient (a) reflects the relationship between the pore ratio and pressure change and can be calculated by the following equation [25]:

$$
a=\frac{e_{i}-e_{i+1}}{p_{i+1}-p_{i}},
$$

where $e$ is the void ratio of the soil and $p$ is the vertical pressure load in the soil.

The compression modulus Es is the relationship between the vertical stress and vertical strain of the soil under confined compression conditions. It can be calculated by the following equation [25]:

$$
E_{s}=\frac{1+e_{i}}{a}
$$

The compressibility index $C c$ is the relation between the change in pore ratio and the change in pressure. It can be calculated by the following equation [25]:

$$
C_{c}=-\frac{e_{i}-e_{i+1}}{\lg p_{i+1}-\lg p_{i}}
$$

Ordinary aeolian sand is a noncohesive material, but the Mu Us Desert aeolian sand contains fine-grained soil that can be shaped; therefore, the conventional consolidation apparatus can be used to test it. The ring cutter diameter is $61.8 \mathrm{~mm}$, and the height is $20 \mathrm{~mm}$. The test material is aeolian sand collected from the foundations of different sections of the Shanxi-Inner Mongolia expressway. The moisture content test uses the natural moisture adopted in each section. Five to eight loading levels were selected (12.5, $25,50,100,200,300,400,500,600$, and $800 \mathrm{kPa})$, the load of the first stage was $12.5 \mathrm{kPa}$, and the amount of deformation of the test was recorded every hour. After the final loading, the data were recorded after 24 hours to obtain the correction coefficient $K$ of the total deformation of this sample.

\section{Analyses of the Test Results}

5.1. SLT Results. To test the treatment effect of the foundation, 2 to 4 points were selected in every test area, and the results are shown in Figure 4. These data illustrated the low bearing capacity of aeolian sand in the Mu Us Desert and indicated that before construction in those areas, the foundation needs to be treated. The test results are shown in Figure 7, which shows the relationship between the pressure and settlement observed by two types of foundations. The figure indicates that as the vertical stress increased, the settlement increased gradually in every test. This means that the stress will significantly influence the soil deformation. We can also see in this figure that except for the settlement curve for the natural foundation, almost all the curves of the settlement for subgrade top surface 2 slightly increased compared to the stress increase.

Figure 7 does not clearly express this phenomenon; therefore, calculating the allowable bearing capacity is necessary. The new problem is that it is difficult to find the $p_{0}$ and $p_{s}$ points in the subgrade settlement curve in the $p-s$ figure, and the solving method uses the relative settlement to obtain the allowance bearing capacity. The value achieved by equation (2) is shown in Table 6.

Table 6 shows that the bearing capacity of the foundation after the treatment changed significantly compared to that before treatment. The highest strength was $460 \mathrm{kPa}$ in the first area before treatment, and the lowest was $36 \mathrm{kPa}$ in the fifth area. The highest strength is $717 \mathrm{kPa}$ in area 2 after reinforcement, and the lowest is $234 \mathrm{kPa}$ in area 5 . Even with the allowable bearing capacity in the subgrade top or natural foundation, the strength is distributed in a wide range, and it is difficult to evaluate the effect of the foundation treatment. The average value is a common index for statistical samples; it reveals the mean level in such data and uses the following equation [26]:

$$
M=\frac{x_{1}+x_{2}+\ldots+x_{n}}{n} .
$$

Two groups of different data may have the same average number, and it is difficult to assess which group is better than the other; thus, the standard deviation can clearly distinguish 


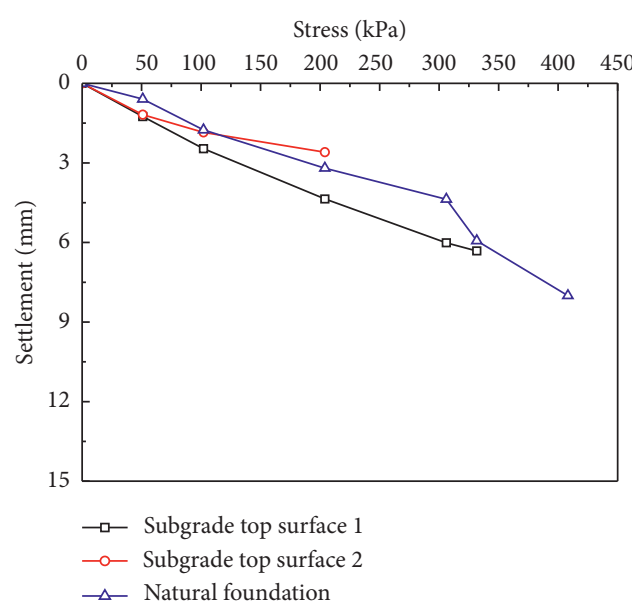

(a)

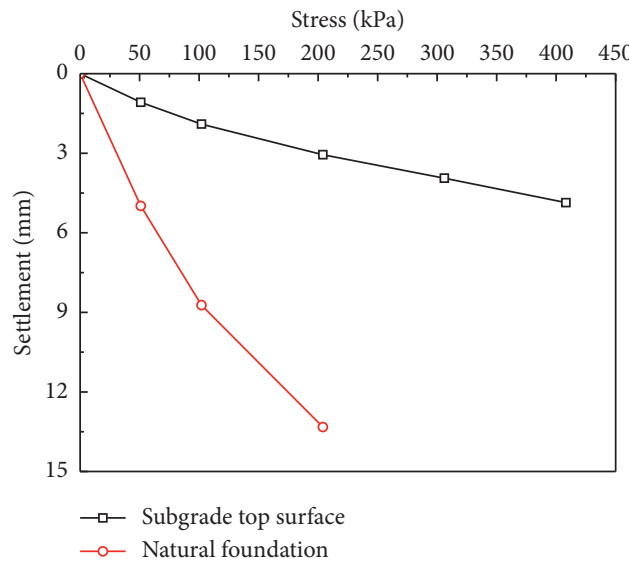

(c)

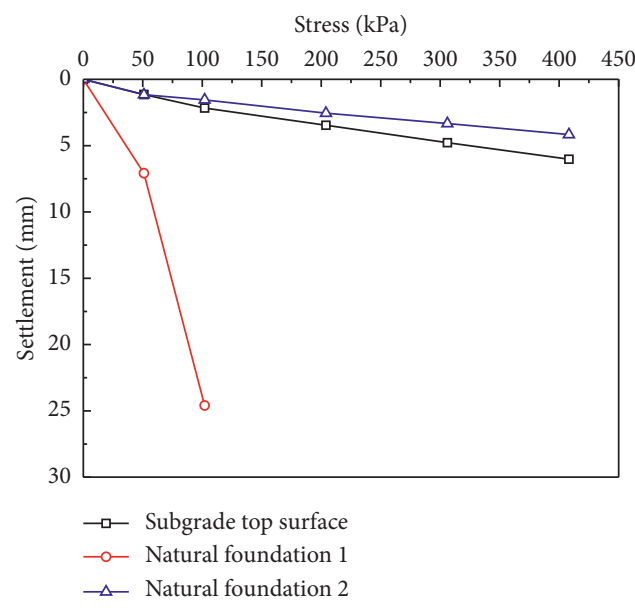

(e)

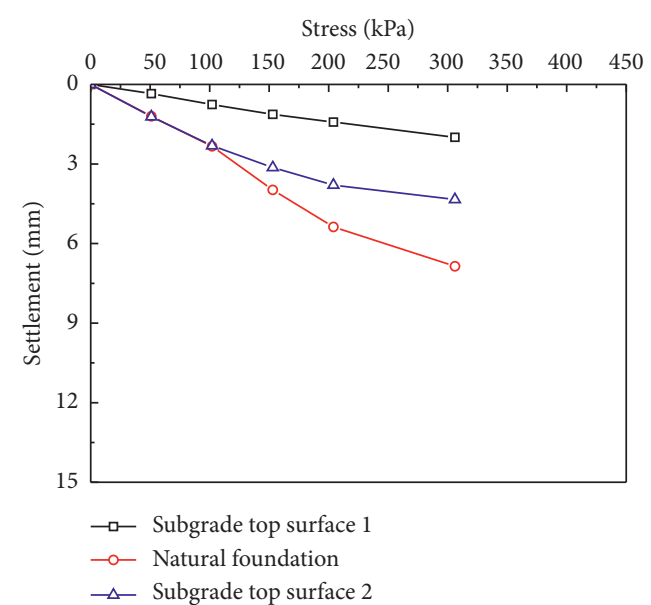

(b)

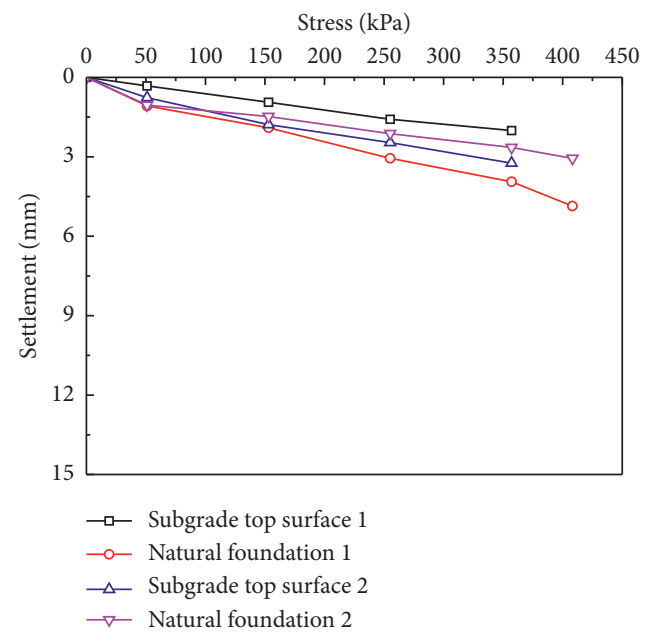

(d)

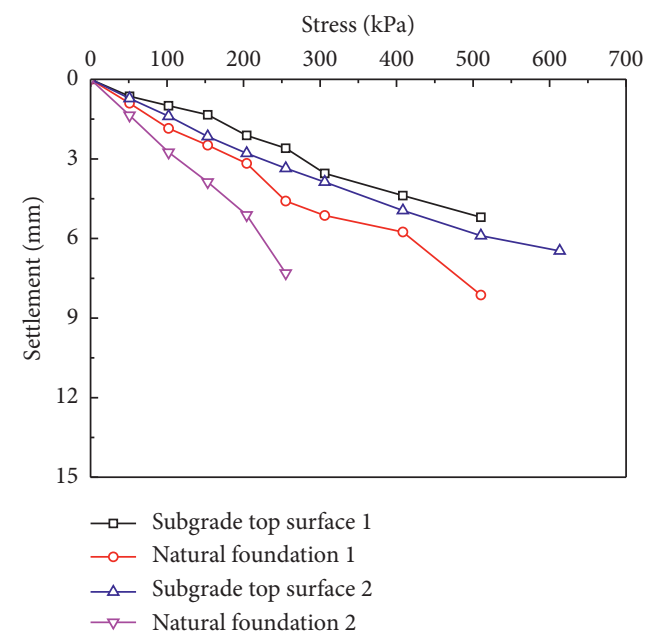

(f)

Figure 7: Results of the $p$-s curve in each test area. (a) Area 1. (b) Area 2. (c) Area 3. (d) Area 4. (e) Area 5. (f) Area 6.

the better group. The standard deviation is the square root of the arithmetic mean or the square of the standard value, and the mean square of the total number of units in the whole, which reflects the discreteness of a data set, can be defined by the following equation [26]:

$$
\sigma=\sqrt{\frac{1}{N} \sum_{i=1}^{N}\left(x_{i}-\mu\right)^{2}}
$$


TABLE 6: Calculated allowance bearing capacity in each testing area.

\begin{tabular}{lcccc}
\hline Area & Subgrade top 1 & Subgrade top 2 & Natural foundation 1 (kPa) & Natural foundation 2 \\
\hline 1 & $234 \mathrm{kPa}$ & $393 \mathrm{kPa}$ & 232 & - \\
2 & $717 \mathrm{kPa}$ & $530 \mathrm{kPa}$ & 255 & - \\
3 & $420 \mathrm{kPa}$ & - & 51 & - \\
4 & - & - & 420 & $460 \mathrm{kPa}$ \\
5 & $320 \mathrm{kPa}$ & $490 \mathrm{kPa}$ & 36 & - \\
6 & $465 \mathrm{kPa}$ & $412 \mathrm{kPa}$ & 166 & $99 \mathrm{kPa}$ \\
\hline
\end{tabular}

Therefore, the calculated average value and standard deviation are shown in Figure 8.

Figure 8 illustrates the strength in different areas before and after the foundation treatment. Before ground treatment, the average total strength $(\mu)$ is $214.9 \mathrm{kPa}$, the standard deviation $(\sigma)$ is $159.8 \mathrm{kPa}$, the upper limit $(\mu+\sigma)$ is $374.6 \mathrm{kPa}$, and the lower limit $(\mu+\sigma)$ is $55.0 \mathrm{kPa}$. In area 1 and area 2 , the allowable bearing capacity of the natural foundation is large because the test sites are near the construction pavement and may be rolled by the construction machine, improving the bearing capacity. In area 3, the allowable bearing capacity of the natural foundation is obviously small, mainly because the test site of the natural foundation is near water, the thickness of the silt layer is large and the settlement is large. The bearing capacity of the soft foundation is obviously insufficient and needs to be addressed. The test results show that the allowable bearing capacity of the natural foundation is larger in area 4 than that of the soft foundation. The allowable bearing capacities of the natural foundation in areas 5 and 6 are obviously small, which indicates that the bearing capacity of the soft foundation is obviously insufficient and must be addressed.

After ground treatment, the average total strength $(\mu)$ is $442.3 \mathrm{kPa}$, the standard deviation $(\sigma)$ is 136.1 , the upper limit $(\mu+\sigma)$ is $578.4 \mathrm{kPa}$, and the lower limit $(\mu-\sigma)$ is $306.2 \mathrm{kPa}$. Compared with the strength before and after treatment, the bearing capacity hardly improved, and the data before treatment exhibited large discreteness. The allowable bearing capacity of the top of the subgrade is small in area 1 because the construction unit does not change the filling section after filling. The allowable bearing capacity of the natural foundation is less than the allowable bearing capacity of the top of the subgrade in area 2, which indicates that the bearing capacity of the soft foundation is insufficient and needs to be addressed. From the test results, it can be seen that replacing the silt with 2 meter of aeolian sand, and adding a geogrid treatment is clearly effective. From the test results in area 3, it can be seen that replacing 1 meter of riprap with 2 meters of aeolian sand and geogrid treatment is clearly effective. From the area 5 test results, it can be seen that the treatment effect is obvious after replacement of aeolian sand, and the bearing capacity of the foundation is improved. From the test results of area 6, it can be seen that the treatment effect of replacing the sand gravel and geogrid is obvious, and the bearing capacity is improved.
5.2. CCT Results. The relationship between stress and settlement is shown in Figure 9. The water content and void ratio have a great influence on foundation settlement. The moisture content and void ratio is significantly higher than that of the other areas, and the settlement is accordingly higher than that of the other areas.

The compression curve is given under the condition of $K_{0}$, and the typical form of the $e$-lgp curve is very smooth at the beginning. When the pressure increases to a certain value, the curve declines sharply, and in most natural soils, the curves are almost a straight line. In Figure 10, this phenomenon also occurs in the characteristics of the Mu Us Desert aeolian sand. When the pressure increased, the straight line decreased. During this process, pressure forced the sand particle to close, and the fiction counteracted this pressure, which acted as the strength of the sand. However, in the final stage, the soil grains were crushed, and the line was inclined.

The coefficient of compressibility is used to assess the compression of the soil, as shown in Table 7. Equations (3) and (4) can be used to calculate the coefficient of compressibility (CC) and modulus of compressibility (MC), and the results can be seen in Table 8 . The coefficient of compressibility is between $0.1 \mathrm{MPa}^{-1}$ and $1.0 \mathrm{MPa}^{-1}$, and the modulus of compressibility is between $2.1 \mathrm{MPa}$ and 15.6 $\mathrm{MPa}$. The CC results are in the range of $0.1 \mathrm{MPa}^{-1}$ to 1.0 $\mathrm{MPa}^{-1}$, and the $\mathrm{MC}$ is in the range of $2.1 \mathrm{MPa}$ to 15.6 MPa. That is, the foundation soil in areas 2 and 3 is a highly compressive soil, and the others are medium compressible soils.

When the stress load is on the soil surface, the force will actually compress the soil particles (smaller part), pore water, and gas are excreted to the soil, and the volume is reduced. The compressibility of the soil shows the characteristics of this change process. Compressibility consists of two aspects: one is the absolute size of the compressive deformation, that is, the amount of settlement, and the other is the amount the compressive deformation changes with time, which is called the consolidation of the soil. To deepen the understanding of the relationship of the soil stress and strain with the calculation of the degree of compressibility of the soil (i.e., settlement), the calculation of compression only considers the uniaxial compression deformation to the lateral deformation and development. 


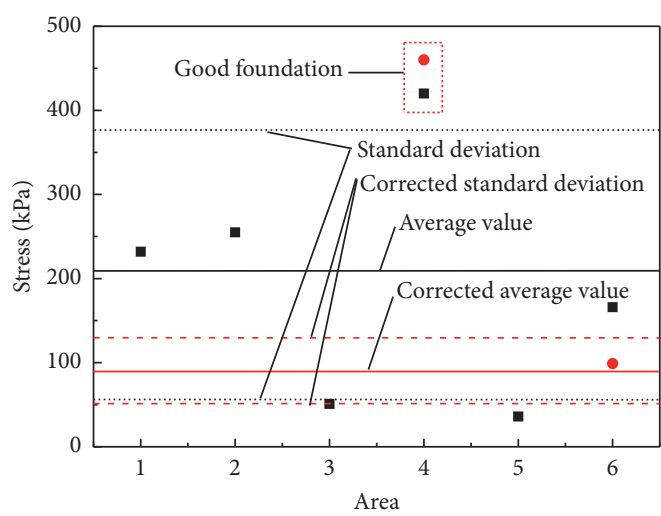

- Natural ground 1

- Natural ground 2

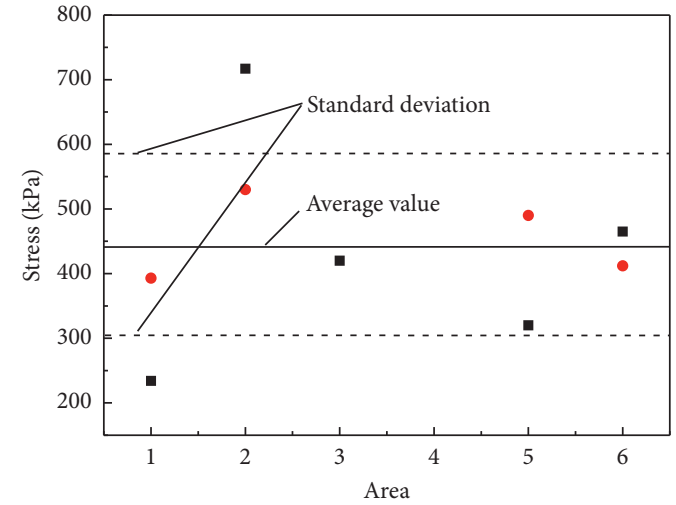

- Subgrade 1

- Subgrade 2

(a)

(b)

Figure 8: Results of the $p$-s curves in each test area. (a) Before foundation treatment. (b) After foundation treatment.

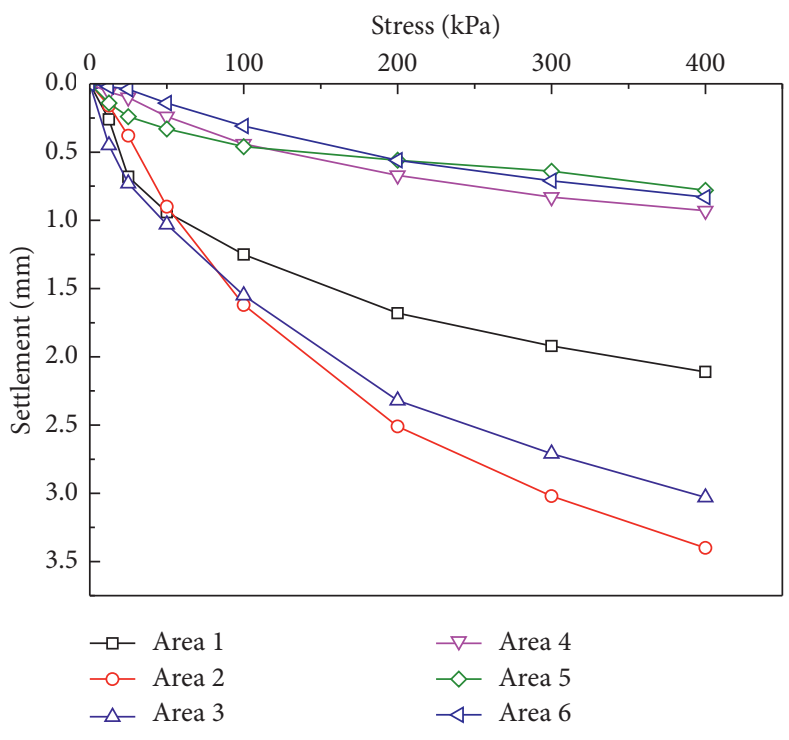

FIgURE 9: Result of the compaction test.

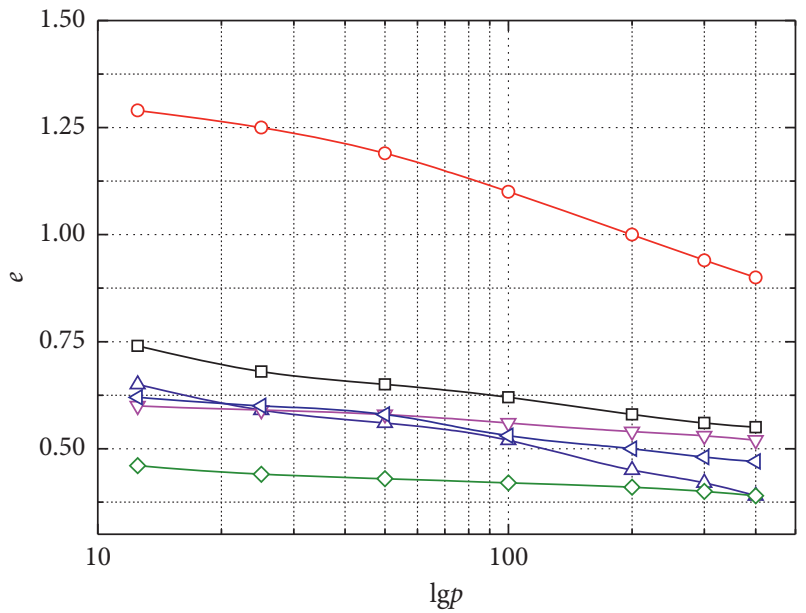

$$
\begin{array}{ll}
\neg-\text { Area } 1 & - \text { Area } 4 \\
\multimap-\text { Area 2 } & \checkmark \text { Area 5 } \\
\neg \text { Area 3 } & \checkmark \text { Area 6 }
\end{array}
$$

Figure 10: Results of the $e$-lgp curve in each test area. 
TABLe 7: Assessment standard for soil compression [27].

\begin{tabular}{lr}
\hline Coefficient of compressibility/a & Assessment \\
\hline $0<\mathrm{a}<0.1 \mathrm{MPa}^{-1}$ & Low compressive soil \\
$0.1 \mathrm{MPa}^{-1} \leq a<0.5 \mathrm{MPa}^{-1}$ & Medium compressible soil \\
$a \geq 0.5 \mathrm{MPa}^{-1}$ & High compressive soil \\
\hline
\end{tabular}

TABLE 8: Coefficient and modulus of the compressibility results.

\begin{tabular}{lccc}
\hline Area & Coefficient of compressibility/a & Modulus of compressibility/Es & Compressibility assessment \\
\hline 1 & 0.4 & 4.1 & Medium \\
2 & 1.0 & 2.1 & High \\
3 & 0.7 & 2.2 & High \\
4 & 0.1 & 15.6 & Medium \\
5 & 0.1 & 14.4 & Medium \\
6 & 0.2 & 7.5 & Medium \\
\hline
\end{tabular}

\section{Conclusion}

In this paper, 6 typical test sites were selected in the Mu Us Desert and reinforced by each method. A series of lab tests and in situ tests were carried out to test the bearing capacity of aeolian sand and the effect of the reinforcement. Based on the results obtained from the present investigation, the following conclusions can be made regarding the bearing capacity of aeolian sand:

(1) Basic physical experience shows that aeolian sand in the $\mathrm{Mu}$ Us Desert has characteristics of a low moisture content, poor cohesion, and easy compaction.

(2) The SLT results indicated that the bearing capacity in a good foundation is very large, reaching $460 \mathrm{kPa}$ in natural ground. The bearing capacity in weak foundations is evidently smaller than that in good foundations, reaching only $55 \mathrm{kPa}$ in natural ground.

(3) The strength of the foundation improved remarkably after foundation treatment by adding a geogrid or replacing it with stone and sand. The largest bearing capacity is $717 \mathrm{kPa}$. The average value after the foundation treatment is $442.3 \mathrm{kPa}$, and the corrected average value before treatment is $88 \mathrm{kPa}$.

(4) The CCT results illustrated that the increase in the mud content and water content can significantly reduce the bearing capacity. The higher water and mud content can result in a larger settlement because water occupies the volume and is easily discharged from the soil during loading, and mud particles can lead to uneven soil gradation.

(5) The coefficient of compressibility and the modulus of compressibility were calculated from 6 test areas. The soils of areas 2 and 3 were highly compressive soil, and the others were medium compressible soil.

\section{Data Availability}

The figure and table data used to support the findings of this study are available from the corresponding author upon request.

\section{Conflicts of Interest}

The authors declare that they have no conflicts of interest.

\section{Acknowledgments}

The authors thank the group of "special foundation treatment technology of Mu Us desert" for their help in the experiences.

\section{References}

[1] H. Tsoar, "Types of aeolian sand dunes and their formation," Lecture Notes in Physics, vol. 582, pp. 403-429, 2008.

[2] Knott, "The structure and pattern of dune-forming winds," Glia, vol. 61, no. 2, pp. 129-139, 1979.

[3] H. Tsoar, "The dynamics of longitudinal dunes," Final technical report, U.S. Army European research office, London, UK, 1978.

[4] I. Livingstone, "Geomorphological significance of wind flow patterns over a Namib linear dune," Aeolian Geomorphology, pp. 97-112, 1986.

[5] J. A. Lee, "A field experiment on the role of small scale wind gustiness in aeolian sand transport," Earth Surface Processes and Landforms, vol. 12, no. 3, pp. 331-335, 1987.

[6] N. Lancaster, Origin of the Gran Desierto Sand Sea, Sonora, Mexico: Evidence from Dune Morphology and Sedimentology, Springer, Dordrecht, Netherlands, 1995.

[7] I. H. Khan, "Soil studies for highway construction in arid zones," Engineering Geology, vol. 19, no. 1, pp. 47-62, 1982.

[8] H. A. Al-Sanad and S. P. Bindra, Soil Mechanics for Road Engineers in Arabian Peninsula, Kuwait University, Kuwait, 1984.

[9] H. A. Al-Sanad, N. F. Ismael, and A. J. Nayfeh, "Geotechnical properties of dune sands in Kuwait," Engineering Geology, vol. 34, no. 1-2, pp. 45-52, 1993.

[10] A. S. Al-Harthy, M. A. Halim, R. Taha, and K. S. Al-Jabri, "The properties of concrete made with fine dune sand," Construction and Building Materials, vol. 21, no. 8, pp. 1803-1808, 2007.

[11] Z. Zhang, H. Gong, Y. Xie, and X. Yang, "The engineering property of aeolian sand in inner Mongolia," Journal of Hebei University of Technology, vol. 35, no. 3, pp. 112-117, 2006.

[12] Y. Yuan, X. Wang, and X. Zhou, "Experimental research on compaction characteristics of aeolian sand," Frontiers of 
Architecture and Civil Engineering in China, vol. 2, no. 4, pp. 359-365, 2008.

[13] Z. Chen and W. Li, "Vibratory parameters and vibratory compacting mechanism of eolian sand," Journal Of Chang'an University (Natural Science Edition), vol. 27, no. 1, pp. 1-6, 2007.

[14] X. Jiang, Z. Sun, Z. Yang, and C. Gao, "Properties and application of aeolian sand," Fly Ash Comprehensive Utilization, no. 1, pp. 65-69, 2018.

[15] M. Al-Ansary, M. C. Pöppelreiter, A. Al-Jabry, and S. R. Iyengar, "Geological and physiochemical characterisation of construction sands in Qatar," International Journal of Sustainable Built Environment, vol. 1, no. 1, pp. 64-84, 2012.

[16] S. A. S. El-Sayed, "Assessing the engineering properties of concrete made with fine dune sands: an experimental study," Arabian Journal of Geosciences, vol. 6, pp. 1-7, 2011.

[17] G. P. Padmakumar, K. Srinivas, K. V. Uday et al., "Characterization of aeolian sands from Indian desert," Engineering Geology, vol. 139-140, no. 6, pp. 38-49, 2012.

[18] R. Yang, L. Ji, and L. Yu, "Research on the compaction mechanism of aeolian sand," Modern Transportation Technology, vol. 7, no. 1, pp. 4-24, 2010.

[19] M. G. M. Elipe and S. López-Querol, “Aeolian sands: characterization, options of improvement and possible employment in construction - the State-of-the-art," Construction and Building Materials, vol. 73, no. 12, pp. 728-739, 2014.

[20] Z. Wu, Geomorphology of Wind-Drift Sands and Their Controlled Engineering, Science Press, Beijing, China, 2003.

[21] Z. Wang, Y. Wu, L. Tan, T. Fu, Y. Wen, and D. Li, "Provenance studies of aeolian sand in $\mathrm{Mu}$ Us Desert based on heavy-mineral analysis," Aeolian Research, vol. 40, no. 10, pp. 15-22, 2019.

[22] H. F. Xing, C. Xu, and Z. M. Shi, "Static plate test," in Situ Test of Geotechnical Engineering, Tongji University, Shanghai, China, 2nd edition, 2015.

[23] GB 50021-2001, Code for Investigation of Geotechnical Engineering, Ministry of Housing and Urban-Rural Development, Beijing, China, 2009.

[24] J. J. Mitchell and S. Kenichi, Soil Formation. Fundamentals of Soil Behavior, John Wiley \& Sons, Hoboken, NJ, USA, 2005.

[25] Z. Y. Chen, J. X. Zhou, and H. J. Wang, Soil Mechanics, Tsinghua University press, Beijing, China, 1992.

[26] Z. Sheng, S. Q. Xie, and C. Y. Pan, Probability Theory and Mathematical Statistics, Higher Education Press, Beijing, China, 4th edition, 2008.

[27] G. X. Li, Y. Z. Yu, and B. Y. Zhang, Soil Mechanics, Tsinghua University Press, Beijing, China, 2nd edition, 2013. 